\title{
Employees as internal audience: how advertising affects employees' customer focus
}

\author{
Mary Wolfinbarger Celsi • Mary C. Gilly
}

Received: 20 March 2007 / Accepted: 9 September 2009 / Published online: 6 October 2009

(C) The Author(s) 2009. This article is published with open access at Springerlink.com

\begin{abstract}
Ad campaigns target consumers with information about the company, its products, and sometimes its employees. Ads also reach the organization's employees and may contain information useful to employees in meeting customer needs. Results from a study involving a high-tech firm indicate that when employees believe ads are effective and value congruent, their customer focus increases. Pride completely mediates the effects of value congruence and effectiveness on customer focus. Organizational identification of employees generally results in a more favorable reaction to ads. A second study involving a regional health facility replicates and extends these findings to include employee portrayal accuracy when employees are featured in ads. Employee portrayal accuracy affects promise accuracy, effectiveness and value-congruence. In addition, employee portrayal accuracy has a direct effect on customer focus.
\end{abstract}

Keywords Employees · Advertising · Customer focus . Internal marketing $\cdot$ Value congruence $\cdot$ Pride

\section{Introduction}

Traditionally, researchers have approached organizational communications as if they are cleanly divisible into one

M. W. Celsi

College of Business Administration,

California State University Long Beach,

1250 Bellflower Blvd.,

Long Beach, CA 90840, USA

e-mail: mwolfin@csulb.edu

\section{C. Gilly $(\bowtie)$}

The Paul Merage School of Business, University of California, SB 401,

Irvine, CA 92697, USA

e-mail: mcgilly@uci.edu of two categories: external or internal. Organizational behavior researchers study the effects of internal communication on employees while marketers study the effects of external communication on consumers. Only limited effort has been invested in understanding the effects of external communications on employees as an internal audience. While advertising is of course targeted at particular external audiences, there nevertheless can be significant spillover effects on audiences that may not have been targeted (Melewar 2003), including employees. The messages created by marketing decision makers potentially produce "meaning both for consumers and for organizations and their members at one and the same time" (du Gay 2000, p. 72).

While organizational behavior researchers recognize the effects that external organizational images can have on employees, particularly focusing on news media coverage (Ashforth and Mael 1989; Dutton et al. 1994), they have not empirically studied and only rarely mention advertising as an external source of organizational images. Yet, "advertising is probably the most visible, recognizable and memorable element of organizational communication" (Ewing et al. 2002, p. 5), and is perhaps the most controllable element of external organizational communications. Moreover, internal organizational identity and external images may be inconsistent (Simões et al. 2005).

Scholars who have studied how employees react to external marketing efforts assert that employees interpret, evaluate, and react to communications of and about their organization (Drumwright 1996; Gilly and Wolfinbarger 1998; Scott and Lane 2000). Our attention here is on the effect of advertising on employee customer focus. Customer focus is "the individual's beliefs about customers...[and] acceptance of the marketing concept" (Allen et al. 1998, p. 9). Employees with customer focus direct their efforts toward understanding and meeting customer needs. 
We spotlight customer focus for several reasons. First, customer focus is an important element of organizational culture that is strongly related to the marketing function. Second, prior research demonstrates that customer focus and business performance are positively related (Best 2004; Jaworski and Kohli 1993; Pinar et al. 2007). A final reason for highlighting customer focus is that advertising, as employees are well aware, is targeted at customers and thus has the potential to evoke and reinforce customerfocused thoughts. Every ad has "implied consumers" who "are assumed to be present in every advertising text as imagined message recipients" (Stern 1994, p. 11). Often information in ads about customers is specific, as when ads picture customers, or supply information about how products, services and the company are being positioned and marketed. Under the right conditions, organizational advertising reminds and intensifies the belief that employees are collectively working toward the common goal of serving customers.

The effect of advertising on the customer focus of employees has yet to be studied despite the fact that advertising can be expected to prompt employees' thoughts about customers. While customer focus is most often conceptualized at the firm level (Bartley et al. 2007; Pinar et al. 2007), researchers recognize that customer focus can be studied at the individual employee level (Allen et al. 1998; Punjaisri and Wilson 2007). Because we are studying individual employee reactions to ads, this level of analysis is most relevant to our study.

Our research about how employee customer focus is affected by their organization's advertising includes the following key constructs: (1) employee organizational identification, (2) ad promise accuracy, (3) value congruence, (4) advertising effectiveness, and (5) pride. Each of these constructs is defined and discussed in the following sections.

\section{Background and hypothesis development}

When employees encounter an image of their organization, "they are prompted to reconsider their role as stakeholders and to reflect on the fit of the organizational image with their own identity" (Scott and Lane 2000, p. 51). Selfschematas are likely to be activated by ads because they are the most fundamental evaluative screen (Debevec et al. 1987; Domzal and Kernan 1993). Ads produced for organizations are especially self-relevant for most employees. Not only do employees evaluate ads directly, they consider how ads are interpreted by outsiders, including friends, families, and customers, because these outsiders make judgments about the character of the organization, and, by extension, about employees of the organization (Gilly and Wolfinbarger 1998).

Organizational membership is often an important element of self-concept (Shamir et al. 1993; Tajfel and Turner 1985), and employees often identify with their organizations. Dutton et al.'s (1994, p. 239) definition of organizational identification is used here: "When they [employees] identify strongly with the organization, the attributes they use to define the organization also define them."

It is widely accepted in the social sciences that people seek information that reinforces their preexisting attitudes and beliefs and that they interpret information that may disconfirm those beliefs to make it consistent with their beliefs (Eagly and Chaiken 1993; Festinger 1957; Fiske and Taylor 1984). Moreover, research on self-affirmation (Steele 1988) and self-justification (Staw 1980) suggests that a positive view of the self is reinforced when one's evaluations of the groups that one identifies with are favorable. Therefore, members who strongly identify with their organization are more likely to believe that the organization is performing well (Dutton et al. 1994). In our study context, this research on self-affirmation suggests that employees who are already strongly identified with the company are likely to evaluate their company's ads in a positive light.

Previous qualitative research reveals that employees commonly judge the accuracy and value congruence of ads (Gilly and Wolfinbarger 1998). As insiders, employees often have extensive knowledge about their companies, and thus they are in a privileged position to evaluate promise accuracy, that is, how likely it is that the organization will consistently fulfill claims made in ads.

Advertising is especially likely to activate selfschematas when ads feature an employee's organization. Enhancing self-focus has been shown to activate central values (Verplanken and Holland 2002). Thus, it is not surprising that employees commonly evaluate the value congruence of ads (Gilly and Wolfinbarger 1998). Ad value congruence is the similarity between personal values and values highlighted in an ad. Advertising inherently makes statements about organizational values, prompting employees to invoke self-relevant values and compare them to portrayed values. For example, ad slogans such as "You're in good hands with Allstate" or Avis' "We try harder" imply a specific organizational value, in this case, taking good care of customers. Other organizational values commonly highlighted in ads include innovation, teamwork, quality, and employee appreciation (Badovick and Beatty 1987). Some values may be implicit in the ad; for example, creativity, fun, or stability are organizational values that may be inferred from executional elements of an ad. 
A great deal of scholarship supports the importance of employee value congruence with supervisors, leaders and organizational culture, and links value congruence to various outcomes including satisfaction, commitment, emotional engagement, trust and performance (Avolio 2000; Chatman 1991; Jung and Avoilo 2000; Kirkpatrick and Locke 1996; Meglino et al. 1989; Shamir et al. 1993). Collectively, research shows that value congruence makes shared meaning and coordinated behavior more likely. With respect to advertising, we expect value-congruent ads to reinforce, strengthen and activate motivational properties attached to portrayed values (Verplanken and Holland 2002). As a result, value congruence in ads is likely to positively engage and motivate employees to support the vision of their organization portrayed in the ad. This discussion suggests:

H1: Employees who identify more strongly with their organization will be more likely to perceive that (a) promises in ads are accurate, and (b) ads are congruent with their values.

In addition to ad promises and value congruence, employees evaluate the likely effectiveness of ads with consumers (Gilly and Wolfinbarger 1998). We use the term "effectiveness" here not in the objective sense of whether ads achieve organizational goals, but as whether employees believe that ads will be successful in gaining consumer attention and generating sales. The persuasion knowledge model (PKM) suggests that viewers of ads commonly use whatever knowledge they have about advertising (Friestad and Wright 1995) to judge the persuasiveness and effectiveness of ads. Employees are especially likely to evaluate their own organizations' ads, given that they have a stake in the success of ads in attaining organizational goals, particularly increased sales.

We predict that promise accuracy and value congruence will affect judgments of ad effectiveness. Previous research suggests that employees link promise accuracy with effectiveness because employees are more likely to feel that their organization can fulfill promises when they are accurate (Gilly and Wolfinbarger 1998). When employees share the values portrayed in the ad, they are also more likely to support the ideas and promises in the ads and believe that other employees in the organization will do so as well. Therefore, we predict:

H2: Ad (a) promise accuracy and (b) value congruence increase perceptions of advertising effectiveness.

Self-conscious emotions, such as pride, play a fundamentally important role in a wide variety of psychological processes (Tracy and Robins 2004). Pride results from positive outcomes attributed to one's own (Michie 2009) or one's own group's efforts. Pride is among the most frequently mentioned personal traits associated with high productivity for employees (White and Locke 1981). In their qualitative study, Gilly and Wolfinbarger (1998) found that employees often express pride in effective advertising. When employees believe an ad is effective, they "bask in the reflected glory" of their group's success (Cialdini et al. 1976).

H3: Advertising effectiveness increases employee pride.

Michie (2009, p. 395) suggests that pride encourages "behavior that conforms to social standards of what is valued or has merit" in the organization. Her study of organizational leaders finds that pride is related to prosocial behaviors, that is, treating others with dignity and respect. Because pride has a motivational component (White and Locke 1981) and because effective ads arouse pride in the context of advertising targeted at customers, employees will be motivated to process and support customer-focused beliefs when they are proud of their firm's advertising. Thus, we predict that:

H4: Employee pride increases customer focus.

Figure 1 depicts the relationships predicted by these hypotheses. The empirical test of the model is discussed next.

\section{Research method: Study 1}

Data were collected from employees at Apex, a Marketing Science Institute member company and a high-technology firm located in the western US with approximately 55,000 employees. At the time of the study, Apex was airing television ads depicting its product as enabling users to experience adventures on the Internet that they could not experience in real life.

Employees were asked to complete an online survey. At Apex, 1,200 invitations were sent to randomly selected nonmarketing employees; 607 were completed for a 51\% response rate. After first filling out items measuring organizational identification, respondents viewed two Apex broadcast commercials online. Employees then evaluated the ads' promise accuracy, value congruence, and effectiveness with consumers. Employees rated their pride in the organization and the degree of customer focus that they experienced as a result of watching the ads. These constructs are considered to be "situated" in that they are a function of cues (in this case, ads) that trigger temporary feelings. Situated pride and customer focus are expected to be necessary conditions for deep-structure adoption of these attitudes (Riketta et al. 2006). In all cases, items were mixed together with items from other constructs. The items appear in the Appendix. 


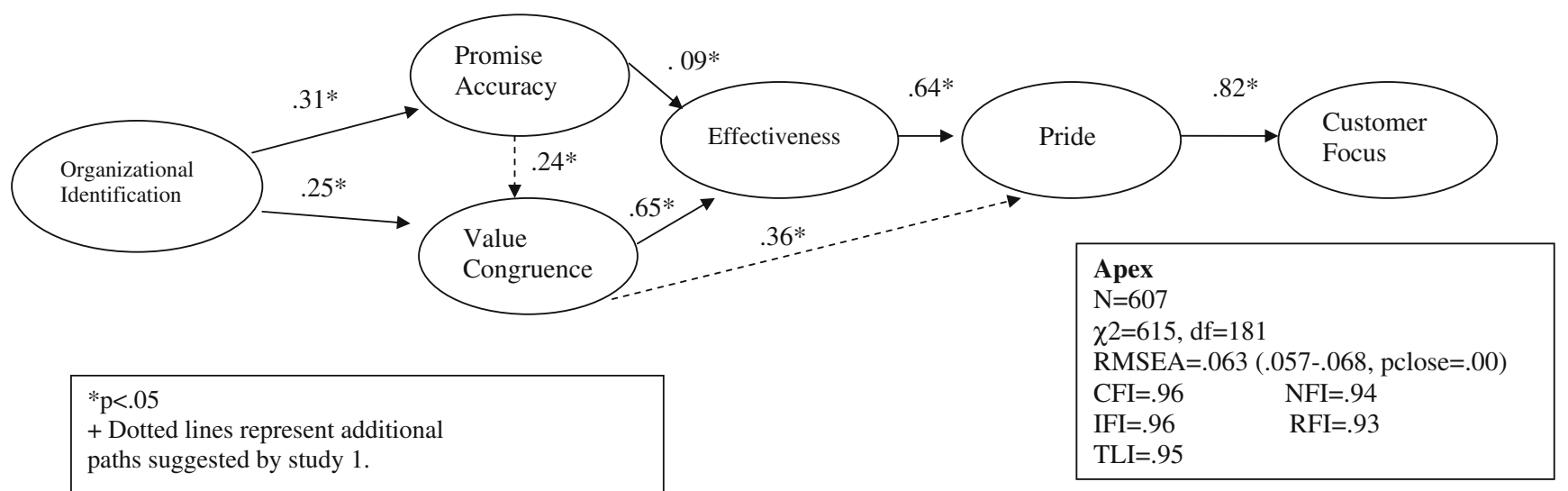

Figure 1 Results for Apex ${ }^{+}$.

\section{Results of Study 1}

We used confirmatory factor analysis to estimate a measurement model to evaluate construct reliability and convergent and discriminant validity. Maximum likelihood estimates of the measurement model were obtained using AMOS. The measurement model has acceptable fit indices: $\chi 2=539.91$ with 174 d.f. and the NFI, RFI, IFI, TLI and CFI all fell between .94 and .96. The RMSEA is .059 (90\% confidence interval of .053 to .065). Each factor loading was positive and significant at the .01 level (see Table 2 in Appendix). Construct reliabilities ranged from .75 to .92, which is acceptable (see Table 2 in Appendix for items, loadings and reliability). The average variances extracted of the constructs is greater than the square of the correlation between any pair of constructs (see Table 1), supporting the discriminant validity of the constructs (Fornell and Larcker 1981).

We fit an initial model that includes the paths indicated by $\mathrm{H} 1-\mathrm{H} 4$ to the data. The overall model fit is acceptable, with a $\chi 2$ of 769.0 with 183 d.f. and fitness measures (NFI,
RFI, CFI, IFI and TLI) between .91 and .94 . A review of the modification indices revealed two significant paths were not included in the model: a path between promise accuracy and value congruence $(\beta=.24)$ and a path between value congruence and pride $(\beta=.36)$. These paths are theoretically plausible and thus were added to the model (see Fig. 1). These two paths suggest that (1) accurate promises are associated with more value-congruent ads, and (2) value congruence affects pride both directly and indirectly through its relationship with effectiveness. When the value congruence $\rightarrow$ pride path is added, $\chi 2$ drops 128.5 with 1 d.f., indicating an improved fit. We also added the promise accuracy $\rightarrow$ value congruence path and $\chi 2$ dropped 25 with 1 d.f., indicating a slightly improved fit. The NFI, RFI, CFI, IFI and TLI are .93 to .96, all of which are good to acceptable fits. The RMSEA is .063 (90\% confidence interval is .057 to .068), which again, indicates an acceptable fit. The final model appears in Fig. 1 (dotted lines indicate added paths).

$\mathrm{H1a}$, organizational identification leads to promise accuracy, is supported $(\beta=.31)$. H1b, suggesting that

Table 1 Correlation matrix for Apex (upper half) and RMH (lower half), AVE on diagonal

\begin{tabular}{|c|c|c|c|c|c|c|c|}
\hline Variable & OrgID & PromAcc & EmpAcc & VC & Effect & Pride & $\mathrm{CF}$ \\
\hline Organizational Identification & $.57 / .61$ & .31 & na & .32 & .16 & .30 & .30 \\
\hline Promise Accuracy & .17 & $.63 / .60$ & na & .30 & .29 & .39 & .33 \\
\hline Employee Accuracy & .52 & .41 & na $/ .68$ & na & na & na & na \\
\hline Value Congruence & .66 & .29 & .71 & $.78 / .70$ & .68 & .79 & .73 \\
\hline Effectiveness & .47 & .29 & .74 & .74 & $.79 / .76$ & .88 & .75 \\
\hline Pride & .65 & .33 & .68 & .79 & .85 & $.87 / .79$ & .81 \\
\hline Customer Focus & .58 & .34 & .72 & .70 & .74 & .75 & $.67 / .70$ \\
\hline
\end{tabular}

*All correlations, $p<.01$, Apex correlations in top, RMH correlations in bottom 
organizational identification increases value congruence, is also supported $(\beta=.25)$. The idea that organizational identification causes employees to view ads more positively is generally supported.

$\mathrm{H} 2 \mathrm{a}$, promise accuracy increases effectiveness, is supported $(\beta=.09)$. Value congruence increases effectiveness $(\beta=.65)$; hypothesis $\mathrm{H} 2 \mathrm{~b}$ is supported.

Effectiveness is related to pride $(\beta=.64)$, and the relationship between pride and customer focus receives support $(\beta=.82)$. Both $\mathrm{H} 3$ and $\mathrm{H} 4$ are supported. Our results suggest that pride mediates the relationship between effectiveness and customer focus, as effectiveness does not have a direct relationship to customer focus when pride is included in the model.

\section{Depicting employees in ads}

Study 1 indicates that employees notice and are influenced by their organization's advertising. However, advertising that features employees provides potentially even more compelling images with which other employees may identify. While merely featuring employees in ads has been shown to result in positive responses from employees in prior studies (Acito and Ford 1980; Gilly and Wolfinbarger 1998), evaluation of ads is nevertheless likely to be strongly influenced by employees' assessment of the similarity between the advertising portrayal and their perceptions of the actual characteristics and behaviors of employees of the company. We define employee portrayal accuracy as the degree to which employee images and behavior are judged to be similar to employees in the organization. When an organization uses employees in its ads, employees are likely to feel more involved with the organization, to evaluate the ad more positively, and to feel that their contributions are valued by their company (Elsbach 1999; Wolfinbarger and Gilly 1991). Just as employees high in organizational identification seek information about ad promises and values consistent with their high regard for the organization, organizational identification is expected to result in the belief that employees portrayed in ads are depicted accurately. When employees are portrayed accurately, the promises in ads are more likely to be judged to be accurate (see Fig. 2 for model).

For organizational members, portraying employees accurately is also important in creating effective ads because these ads will be associated with authenticity and integrity (Gilly and Wolfinbarger 1998), which will lead employees to believe that the organization is positioning itself in the marketplace in a way that is perceived as genuine; the external image that customers are being sold is "real," credible and implementable. Thus, in addition to examining
H1-H4 in the context of ads featuring employees, we suggest:

H5: Organizational identification increases employee portrayal accuracy in ads.

H6: Employee portrayal accuracy in ads increases (a) ad promise accuracy, and (b) ad effectiveness.

\section{Research method: Study 2}

To replicate and extend Study 1, an organization that depicted employees in its ads was recruited. Regional Medical Health (RMH), is a general medical and surgical hospital located in California with a total of 376 beds. At the time of data collection, RMH was running full-page magazine ads that featured doctors using advanced techniques and technologies. In addition to the data collected in Study 1, RMH respondents also evaluated the accuracy of employee images (see Table 2 in Appendix).

At RMH, about 5,000 invitations went out by e-mail to staff, faculty, and residents, but only about 3,730 of those went to individual e-mail accounts (the rest were sent to email-enabled groups and distribution lists). A total of 472 nonmarketing employees completed the survey. The higher rate of completion at Apex may reflect a high level of comfort with the company intranet and technology in general. Another factor in the lower response rate for RMH may have been the somewhat longer length of the survey, which included additional questions concerning employee image and other items not reported here.

\section{Results of Study 2}

Confirmatory factor analysis was used to estimate a measurement model to evaluate construct reliability and convergent and discriminant validity. Maximum likelihood estimates of the measurement model were obtained using AMOS. The measurement model had acceptable fit indices: $\chi 2=2588.68$ with 510 d.f. and the NFI, RFI, IFI, TLI and CFI all fall between .90 and .93 . The RMSEA is .051 (90\% confidence interval of .049 to .053). Each factor loading is positive and significant at the .01 level. Construct reliabilities range from .76 to .95 , all of which are acceptable (see Table 2 in Appendix for items, loadings and reliabilities). The average variances extracted of the constructs is greater than the square of the correlation between any pair of constructs (see Table 1), supporting the discriminant validity of the constructs (Fornell and Larcker 1981).

We fit an initial model that includes the paths indicated by $\mathrm{H} 1-\mathrm{H} 4$ to the data. We also included the two additional paths suggested by Study 1: a path between promise 


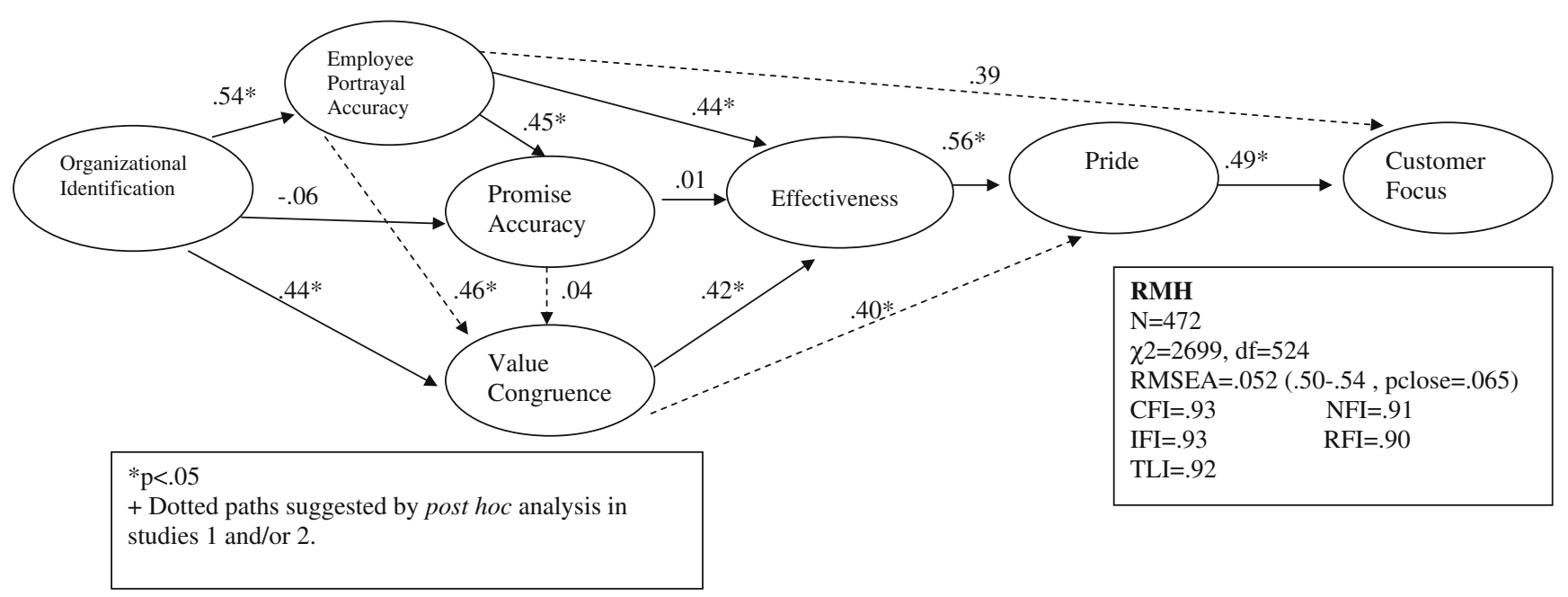

Figure 2 Results for $\mathrm{RMH}^{+}$.

accuracy and value congruence and a path between value congruence and pride. The relationship between promise accuracy and value congruence in Study 2 is not significant $(\beta=.04, p=$ n.s.). The two variables are correlated at $.29(p<.05$, see Table 1$)$, but the inclusion of employee accuracy fully mediates the relationship between promise accuracy and value congruence. The relationship between value congruence and pride is similar to that in Study 1 ( $\beta=.36$ in Study 1 vs. .40 in Study 2 ). The $\chi^{2}=2,929$ with 528 d.f. for this model. Fitness statistics vary from .89 to .92 , with RMSEA $=.054(90 \%$ confidence interval, 052 to .056).

While the fitness indices are acceptable, modification indices suggest that we should consider adding two paths: one from employee portrayal to value congruence $(\beta=.46)$ and a direct path from employee portrayal to customer focus $(\beta=.39)$. These two new paths are theoretically plausible, and suggest that employee portrayal has an additional indirect and direct effect on the outcome variable customer focus. Adding the employee portrayal accuracy $\rightarrow$ value congruence path drops $\chi^{2} 104.7$ for 2 d.f. Adding the employee portrayal accuracy $\rightarrow$ customer focus path drops $\chi 2$ an additional 125 with 2 d.f. The new model with these two additional paths has $\chi 2=2,699$ with 524 d.f. (see Fig. 2). The NFI, RFI, CFI, IFI and TLI vary from .90 to .93 , which generally indicates an acceptable fit. The RMSEA equals .052 (Lo 90=.05 and Hi 90=.054).

H1a, organizational identification leads to promise accuracy, is not supported ( $\beta=-.06, p=$ n.s.). Organizational identification and promise accuracy are correlated in the RMH sample $(r=.17, p<.05$, see Table 1$)$; however, employee portrayal fully mediates the relationship between organizational identification and promise accuracy. H1b, suggesting that organizational identification increases value congruence, is supported $(\beta=.41)$. H5, which suggests that organizational identification raises employee portrayal accuracy, is supported $(\beta=.54)$. As well, H6 is supported: employee portrayal accuracy does result in stronger ratings of promise accuracy $(\beta=.45)$ and effectiveness $(\beta=.44)$.

$\mathrm{H} 2 \mathrm{a}$, promise accuracy increases effectiveness, is not supported $(\beta=.01, p=$ n.s. $)$. While the two variables are correlated (see Table 1), the inclusion of employee portrayal accuracy as a predictor of effectiveness dampens the relationship between promise accuracy and effectiveness. On the other hand, value congruence has a strong relationship to effectiveness $(\beta=.42) ; \mathrm{H} 2 \mathrm{~b}$ is supported.

Effectiveness is related to pride $(\beta=.56)$, and the relationship between pride and customer focus is significant $(\beta=.49)$. Both $\mathrm{H} 3$ and $\mathrm{H} 4$ are supported. As in Study 1 , pride completely mediates the relationship between effectiveness and customer focus; however, the results of Study 2 suggest a new wrinkle: employee portrayal has a direct effect $(\beta=.39)$ on customer focus as well as indirect effects through value congruence and effectiveness.

\section{Discussion}

Typically, research on organizational identity has focused either on "identity of," which is organization and marketfocused, or "identification with," which focuses on the relationship between the individual and the group or organization (Hatch and Schultz 2000). Our research helps elucidate the relationship between external communications of the organization and the internal reactions 
of the company's members to the organizational and employee information featured in ads. We next discuss the theoretical and managerial implications of our major findings.

\section{Ad effectiveness matters to employees}

Cognitive theories of emotion (Michie 2009) suggest emotions (such as pride) are generated in response to events (such as ads) that are assessed in relation to their implications for an individual's well-being (such as employer success). Results from both studies indicate that pride mediates the relationship between employees' judgments of the effectiveness of ads and customer focus. Employees use their persuasion knowledge (Friestad and Wright 1994) to discern whether ads will be effective with consumers. While the persuasion knowledge model is useful in considering employee response to ads, our findings suggest that people use persuasion knowledge in ways other than simply to cope with persuasion attempts as Friestad and Wright (1994) suggest.

Most employees do not have access to results of research conducted by advertising decision makers on ad effectiveness. Sharing information with employees that shows that advertising is effective with consumers is likely to increase pride and customer focus when employees view their organization's ads.

Value congruence and employee portrayal accuracy make effective ads

Three attributes of ads are related to judgments of advertising effectiveness: value congruence, employee portrayal accuracy and promise accuracy. The relationship of promise accuracy and effectiveness, however, is small in Study 1 and is fully mediated by employee portrayal accuracy in Study 2. In their qualitative study, Gilly and Wolfinbarger (1998) focus on the role of promise exaggeration in employee ad evaluation. In contrast to that study, this research suggests that exaggeration in advertising is somewhat acceptable to employees. It may be that there is a "zone of acceptability" around advertising promises. Employees are consumers, and previous research establishes that consumers expect exaggeration in advertising. A review of six decades of research indicates that $70 \%$ of consumers believe that advertising is often untruthful (Calfee and Ringold 1994). As well, James and Alman (1996) found that consumers expect puffery in nearly all types of advertising. If consumers expect a bit of exaggeration in ads, it makes sense that employees will "forgive" a bit of puffery in their own organization's ads.

Brand images that appeal to customers do not always appeal to employees (Chun and Davies 2006). While employees generally recognize that advertising messages are targeted at consumer segments whose values they do not share, they nevertheless dislike ads that feature objectionable values (Gilly and Wolfinbarger 1998). While a certain amount of puffery in product claims is expected and acceptable, our results suggest that portraying values and employees inaccurately is much less acceptable.

When ads feature incongruent values and inaccurate employee portrayals, employees' judgments of advertising effectiveness decline. Moreover, employee portrayal accuracy has multiple indirect as well as a direct effect on customer focus. Thus, if employees are to be featured in advertising, it is essential that decision makers understand whether or not portrayed employees have attributes and behaviors that are largely consistent with employees' group self-concept.

Employees take pride in effective ads, but value congruence also matters

Organizational identification theory says employees want to be a part of something they see as successful, and organizations that have effective ads are more likely to be successful. Thus, consistent with Cialdini et al.'s (1976) research, employees take pride in successful advertising. Employees' family and friends see ads as well, and discuss them with employees (Gilly and Wolfinbarger 1998), thus enhancing organizational pride when ads are judged to be successful, and diminishing pride when ads are ineffectual.

Employers who have campaigns that are value congruent and effective with consumers should leverage those campaigns internally. The ads may be featured at company meetings, on the intranet, or in the case of magazine ads, posted prominently in the organization. This advice is especially relevant when employees are featured in ads, which tends to heighten employee responsiveness to the ads.

Customer focus is enhanced when employees take pride in organizational ads and when employees are portrayed accurately

At both companies studied, pride fully mediates the relationship between advertising effectiveness and customer focus. Value congruence affects pride directly and indirectly via effectiveness. Thus, when advertising is effective and value congruent, employees are more likely to take pride in their organization's ad campaign. This pride is connected to an ad campaign focused on customers; thus employees are more likely to think customer-focused thoughts when they judge ads to be effective and value congruent. Pride has a motivational component and is associated with high productivity in employees (White and Locke 1981). When 
pride is aroused by organizational advertising, it leads to increased customer focus.

Organizational identification increases employees' positive evaluation of ads

In both organizations, organizational identification is associated with more positive reactions to ads. Stronger organizational identification results in employees rating promise accuracy, employee portrayal accuracy, and value congruence more highly. Employees who identify with their companies are more willing to see ads as being congruent with their values. These findings suggest that organizational identification broadens the acceptability of values portrayed in company advertising, supporting research in other contexts that people interpret information in ways that confirm their existing beliefs (Eagly and Chaiken 1993; Fiske and Taylor 1984).

When employee identification with an organization is strong, companies can use advertising along with internal communications to reinforce newly desired organizational values, as long as these values are not dramatically inconsistent with existing values. Perhaps employees choose organizations that share their values, much as consumers prefer brands that share their values (Chong 2007). When employees already believe that the organization shares their values, they evaluate ads through that lens.

By leveraging ads internally, leaders are able to engage the emotional involvement of their employees to build identification, value congruence, pride and performance. Developing a shared vision is an important component of the transformational process; thus, leaders should evaluate external campaigns for their potential to be used in internal communications as well.

\section{Limitations and future research}

There are limitations to our study. Employees were exposed to two ads from their company's ad campaign during an online survey. At Apex, the campaign was national, and was posted on the company intranet, so there is a strong possibility that employees had been previously exposed to the ad campaign. The placement of the RMH ad was in a local magazine that was less likely to have been seen previously by employees. At $\mathrm{RMH}, 39 \%$ of employees had seen the ad campaign, while $61 \%$ had not. Our study shows that an advertising campaign can evoke situated pride and customer focus, whether or not the campaign has been previously viewed.

Of course, there are internal/external validity trade-offs in tightly controlled lab studies and surveys. While a laboratory experiment enables control for organizational and ad characteristics, the tradeoff is the loss of context: real employees having real responses to actual ads. But an experimental study would complement our research. As well, it may be that portraying employees in service organization ads has greater effects on employee customer focus than portraying them in non-service industry ads. Future research should explore this possibility.

Longitudinal research should be conducted where employee attitudes toward the organization are measured before, during and after a particular ad campaign. This might be a particularly fruitful study if the ads are explicitly targeted at both customers and employees. Given the importance of employee portrayal accuracy, greater attention should be given to the factors that influence employees' judgment of this attribute. As well, more insight is needed into the small effects on effectiveness and value congruence we report for promise accuracy.

Evaluation of organizational advertising may both influence and be influenced by organizational identification. Therefore, the effects of ad campaigns on organizational identity should also be examined. And, a research design that includes managerial assessment of employees' actual customer-focused behaviors would provide strong evidence for links between advertising and customer focus.

\section{Conclusion}

Ads targeted at consumers also have effects on employees. It is particularly important to employees for ads to be effective and value congruent. Companies can leverage advertising internally whenever ads are effective and value congruent because such ads increase the salience of customer focus for employees. Whenever campaigns are incongruent with employee values or perceived to be ineffective, organizations can limit employee exposure if possible or explain the strategy behind the ads to dampen negative effects on their internal audience. Organizational communications should highlight the probable or actual effectiveness of ads when selling the campaign internally. It is particularly important to feature employees accurately in the eyes of most employees, as the judgment of employee portrayal accuracy has multiple effects on employee evaluations of ads. When employees are featured accurately, management has a golden opportunity to leverage advertising internally to increase organizational pride and customer focus.

Acknowledgements Both authors contributed equally to this work, which was supported by a grant from the Marketing Science Institute. The authors would like to thank Cristina Gibson for her comments on an earlier draft of this paper; they also thank the organizations that participated in the research.

Open Access This article is distributed under the terms of the Creative Commons Attribution Noncommercial License which permits any noncommercial use, distribution, and reproduction in any medium, provided the original author(s) and source are credited. 


\section{Appendix}

Table 2 Measurement items and factor loadings

Constructs

Value Congruence (Construct reliability $=.90, .85$ )

Apex RMH

I'm proud of the values expressed in the ads.

The organizational values implied by the ads are the values and beliefs we should be highlighting in our ads.

The values featured in the ads are similar to my own values.

Ad Promise Accuracy (reverse scored) (Construct reliability $=.75, .76$ )

The product/service is not as good as it is shown in the ad.

The ads make exaggerated claims.

The ads promise more than Apex/Regional Health actually delivers.

Advertising Effectiveness (Construct reliability $=.94, .92$ )

I believe the ads will increase sales of Apex's/Regional Health's services.

I believe that the ads will be well liked by customers

The ads effectively raise the visibility of Apex/Regional Health

The ads are effective.

Employee Portrayal Accuracy (Construct reliability=.87)

Employees are accurately portrayed.

Employees are shown in ads as they really are.

I believe many employees in the organization are similar to those portrayed in the ad.

Employees can live up to the image shown in our advertising.

Organizational Identification (Construct reliability $=.78, .82$ )

I am proud to tell others I am part of Apex/Regional Health.

I care about the fate of Apex/Regional Health.

Apex's/Regional Health's successes are my successes.

I am willing to put in a great deal of effort—beyond that normally expected—in order to help Apex/Regional Health be

successful.

Pride $($ Construct reliability $=.95, .91)$

The ads make me proud of Apex/Regional Health

Seeing the ads makes me feel good about Apex/Regional Health.

I enjoy telling others about the ads.

Customer Focus (Construct reliability $=.86, .89$ )

The ads tell me something about who our customers are or what our customers want.

Seeing these ads reminds me that doing my job well helps Apex/Regional Health serve customers better.

\section{References}

Acito, F., \& Ford, J. D. (1980). How advertising affects employees. Business Horizons, 23, 53-59.

Allen, C. T., McQuarrie, E. F., \& Barr, T. F. (1998). Implementing the marketing concept one employee at a time: Pinpointing beliefs about customer focus as a lever for organizational renewal. Cambridge: Marking Science Institute, Report No. 98-125.

Ashforth, B. E., \& Mael, F. (1989). Social identity theory and the organization. Academy of Management Review, 14(1), 20-39.

Avolio, B. J. (2000). E-leadership: implications for theory, research, and practice. Leadership Quarterly, 11(4), 615-669.
Badovick, G. J., \& Beatty, S. E. (1987). Shared organizational values: measurement and impact upon strategic marketing implementation. Journal of the Academy of Marketing Science, 15(1), 19-27.

Bartley, B., Gomibuchi, S., \& Mann, R. (2007). Best practices in achieving a customer-focused culture. Benchmarking: An International Journal, 14, 482-496.

Best, R. J. (2004). Market-based management: Strategies for growing customer value and profitability (3rd ed.). Upper Saddle River: Prentice Hall.

Calfee, J. E., \& Ringold, D. J. (1994). The 70\% majority: enduring consumer beliefs about advertising. Journal of Public Policy \& Marketing, 13(2), 228-238. 
Chatman, J. A. (1991). Matching people and organizations: selection and socialization in public accounting firms. Administrative Science Quarterly, 36(3), 459-484.

Chong, M. (2007). The role of internal communication and training in infusing corporate values and delivering brand promise: Singapore airlines' experience. Corporate Reputation Review, 10, 201-212.

Chun, R., \& Davies, G. (2006). The influence of corporate character on customers and employees: exploring similarities and differences. Journal of the Academy of Marketing Science, 34(2), 138146

Cialdini, R. B., Borden, R. J., Thorne, A., Walker, M. R., Freeman, S., \& Sloan, L. R. (1976). Basking in reflected glory: three (football) field studies. Journal of Personality and Social Psychology, 34 (3), 39-50

Debevec, K., Spotts, H. E., \& Kernan, J. B. (1987). The self-reference effect in persuasion: implications for marketing strategy. Advances in Consumer Research, 14(1), 417-420.

Domzal, T. J., \& Kernan, J. B. (1993). Creative features of globallyunderstood advertisements. Journal of Current Issues \& Research in Advertising, 16(1), 29-48.

Drumwright, M. E. (1996). Company advertising with a social dimension: the role of noneconomic criteria. Journal of Marketing, 60(4), 71-87.

du Gay, Paul. (2000). Markets and Meanings: Re-imagining Organizational Life. In M. Schultz \& M. J. Hatch (Eds.), The expressive organization: Linking identity, reputation, and the corporate brand (pp. 66-76). Oxford: Oxford University Press.

Dutton, J. E., Dukerich, J. M., \& Harquail, C. V. (1994). Organizational images and member identification. Administrative Science Quarterly, 39(2), 239-263.

Eagly, A. H., \& Chaiken, S. (1993). The psychology of attitudes. New York: Harcourt Brace Jovanovich.

Elsbach, K. D. (1999). An expanded model of organizational identification. Research in Organizational Behavior, 21, 163201.

Ewing, M. T., Pitt, L. F., de Bussy, N. M., \& Berthon, P. (2002). Employment branding in the experience economy. International Journal of Advertising, 21(1), 3-22.

Festinger, L. (1957). A theory of cognitive dissonance. Stanford: Stanford University Press.

Fiske, S. T., \& Taylor, S. E. (1984). Social cognition. New York: Random House.

Friestad, M., \& Wright, P. (1994). The persuasion knowledge model: how people cope with persuasion attempts. Journal of Consumer Research, 21, 1-31.

Friestad, M., \& Wright, P. (1995). Persuasion knowledge: lay people's and researchers' beliefs about the psychology of advertising. Journal of Consumer Research, 22, 62-74.

Fornell, C., \& Larcker, D. F., (1981). Evaluating structural equation models with unobservable variables and measurement error. Journal of Marketing Research, 18(1), 39-50.

Gilly, M. C., \& Wolfinbarger, M. (1998). Advertising's internal audience. Journal of Marketing, 62, 69-88.

James, E. L., \& Alman, K. C. (1996). Consumer expectations of the information content in advertising. International Journal of Advertising, 15(1), 75-88.

Jaworski, B. J., \& Kohli, A. (1993). Market orientation: antecedents and consequences. Journal of Marketing, 57, 53-70.

Jung, D. I., \& Avoilo, B. J. (2000). Opening the black box: an experimental investigation of the mediating effects of trust and value. Journal of Organizational Behavior, 21(8), 949-965.
Kirkpatrick, S. A., \& Locke, E. A. (1996). Direct and indirect effects of three core charismatic leadership components on performance and attitudes. Journal of Applied Psychology, 81(1), 36-51.

Meglino, B. M., Ravlin, E. C., \& Adkins, C. L. (1989). A work values approach to corporate culture: a field test of the value congruence process and its relationship to individual outcomes. Journal of Applied Psychology, 74(3), 424-433.

Melewar, T. C. (2003). Determinants of the corporate identity construct: a review of the literature. Journal of Marketing Communications, 9(4), 195-220.

Michie, S. (2009). Pride and gratitude: how positive emotions influence the prosocial behaviors of organizational leaders. Journal of Leadership \& Organizational Studies, 15(4), 393-403.

Pinar, M., Crouch, H. L., \& Pinar, C. M. (2007). Relationship between customer focus, innovation, and committed people and their impact on business performance: a case of Turkish firms. Journal of Euromarketing, 16(3), 37-49.

Punjaisri, K., \& Wilson, A. (2007). The role of internal branding in the delivery of employee brand promise. Journal of Brand Management, 15, 57-70.

Riketta, M., Van Dick, R., \& Rousseau, D. M. (2006). Employee attachment in the short and long run: antecedents of situated and deep-structure identification. Zeitschrift für Personalpsychologie, 5(3), 85-93.

Scott, S. G., \& Lane, V. R. (2000). A stakeholder approach to organizational identity. Academy of Management Review, 25(1), 43-62.

Shamir, B., House, R. J., \& Arthur, M. B. (1993). The motivational effects of charismatic leadership: a self-concept based theory. Organizational Science, 4, 577-594.

Simões, C., Dibb, S., \& Fisk, R. (2005). Managing corporate identity: an internal perspective. Journal of the Academy of Marketing Science, 33(2), 153-168.

Staw, B. M. (1980). Rationality and Justification in Organizational Life. In B. M. Staw \& L. L. Cummings (Eds.), Research in organizational behavior (Vol. 2, pp. 45-80). Greenwich: JAI.

Steele, C. M. (1988). The Psychology of Self-Affirmation: Sustaining the Integrity of the Self. In L. Berkowitz (Ed.), Advances in experimental social psychology (Vol. 21, pp. 261-302). New York: Academic.

Stern, B. (1994). Authenticity and the textual persona: postmodern paradoxes in advertising narrative. International Journal of Research in Marketing, 11(4), 387-400.

Tajfel, H., \& Turner, J. C. (1985). The Social Identity Theory of Intergroup Behavior. In S. Worchel \& W. Austin (Eds.), Psychology of intergroup relations (2nd ed., pp. 7-24). Chicago: Nelson-Hall.

Tracy, J. L., \& Robins, R. W. (2004). Putting the self into selfconscious emotions: a theoretical model. Psychological Inquiry, 15(2), 103-125.

Verplanken, B., \& Holland, R. W. (2002). Motivated decision making: effects of activation and self-centrality of values on choices and behavior. Journal of Personality \& Social Psychology, 82(3), 434-447.

White, F. M., \& Locke, E. A. (1981). Perceived determinants of high and low productivity in three occupational groups: a critical incident study. Journal of Management Studies, 18(4), 375378.

Wolfinbarger, M. F., \& Gilly, M. C. (1991). A conceptual model of the impact of advertising on service employees. Psychology and Marketing, 8, 215-237. 